\title{
Traditional Tropical Root Crop Technology: Some Interactions with Modern Science
}

\section{G. Coursey}

\section{Introduction $^{1}$}

The tropical world, within which most of the less developed countries (ldes) lie, includes many different ecosystems, with widely differing food production systems. Although in the ldes as in the temperate world grains are the most important staple foods, providing the main calorific bases of most diets, in many parts, especially of the humid tropics, root crops are of equal or even greater local importance. The most important of these are cassava, yams, cocoyams, sweet potatoes and white potatoes [Coursey and Haynes 1970), whose total production is now around $185 \mathrm{mn}$ tons per annum, thus providing the basic food for between 400 and $500 \mathrm{mn}$ people across the tropical world. They are very largely produced from smallscale, subsistence-level production systems, rather than from large-scale field operations and the technologies employed both in their production and their post-harvest utilisation are usually simple and founded on long-established traditional practice. Under humid tropical ecosystems, root crops are often far more productive than grains, whether in terms of production of available energy per hectare per year [de Vries et al 1967] or, especially in the case of cassava, in terms of labour input required to provide a given amount of food [Coursey and Haynes 1970]. This last factor is of major importance to the small farmer of the tropics, who has little or no access to mechanical aids, nor often even to draught animals. Table 1 gives global production statistics for the major tropical root crops. Cassava production has increased rapidly in recent decades, as has white potato: yam and taro production has remained virtually static, while sweet potatoes appear to be declining, except in certain areas.

\section{Principles of Post-harvest Technology of Tropical Root Crops}

It is now generally accepted that food conservation, leading to the reduction of food loss and therefore to increased food availability, requires considerably less energy and other inputs than the production of the same amount of food. Thus post-harvest technology is of especial importance not only in improving the

'The concepts expressed in this article are those of the author personally and do not necessarily represent the official viewpoint of the Tropical Products Institute. economies of food availability, but also in minimising the total impact of food production operations on the environment. Reduction of post-harvest losses also provides an opportunity to reduce pressure on land while providing the same amount of food for consumption, thus helping to reduce the environmental impact of agriculture [FAO/UNEP 1981].

The various tropical root crops which are listed in Table 1 produce different types of edible organ-roots, root tubers or stem tubers - which vary considerably in their post-harvest behaviour, and therefore in the type of post-harvest technology that is most appropriate. There are, however, a number of basic biological principles that apply to all the commodities, and, indeed, to other perishable plant foods. These will be discussed later. The overall magnitude of post-harvest loss can be extremely high: conservative estimates [Coursey 1972; Coursey and Booth 1977; Tindall and Proctor 1980] suggest that around 25 per cent of all perishable food crops, of which the root crops are the most important, are lost between harvesting and consumption, although variations are so great that examples of physical loss could be quoted of almost any figure between nought and 100 per cent [Coursey 1982].

Studies in the area of post-harvest technology have so far mainly concentrated on grains and other durable products which are stored dry, usually at moisture contents below about 12 per cent. In these products, post-harvest deterioration is largely caused by attack of external agents such as insects, moulds or rodents and not from endogenous factors. Most of the lesser amount of work undertaken on perishable crops has concentrated on high-unit-cost horticultural products such as fruits and vegetables rather than on the lowunit-cost staple foods such as root crops. Different approaches are therefore necessary when dealing with tropical root crop products and in many cases traditional technologies, developed in the distant past within subsistence agricultural societies, may be especially appropriate. During the last decade or so, much effort has been devoted by bilateral and multilateral aid agencies to research and development under designations such as 'rural technology', 'grassroots technology', 'small-scale technology', 'inter- 


\section{The principal tropical root crops}

\begin{tabular}{|c|c|c|}
\hline common names & botanical names & $\begin{array}{l}\text { estimated production } \\
\text { in ldcs } \\
\text { megatonnes/annum }\end{array}$ \\
\hline $\begin{array}{l}\text { cassava (tapioca, manioc, mandioca } \\
\text { or yuca) }\end{array}$ & $\begin{array}{l}\text { Manihot esculenta Crantz (often, } \\
\text { incorrectly, } M \text {. utilissimma, Pohl.) }\end{array}$ & 100 to 120 \\
\hline yam (igname, name) & $\begin{array}{l}\text { Dioscorea rotundata Poir., D. cayenensis } \\
\text { Lam., D. alata L., D. esculenta (Lour.) Burk. } \\
\text { and some minor Dioscorea spp. }\end{array}$ & 18 to 22 \\
\hline sweet potato (batata) & Ipomoea batatas (L.) Lam. & 15 to 20 \\
\hline potato ('white' or 'Irish') & $\begin{array}{l}\text { Solanum tuberosum L. (and } S . \text { tuberosum } \\
\quad \times S . \text { andigenum hybrids) }\end{array}$ & 25 to 30 \\
\hline \multicolumn{3}{|l|}{ the edible aroids: } \\
\hline taro, dasheen, eddoc, 'old cocoyam' & Colocasia esculenta (L.) Schott & 4 to 6 \\
\hline tannia, ocumo, 'new cocoyam' & Xanthosoma sagittifolia (L.) Schott & \\
\hline elephant yam & $\begin{array}{l}\text { Amorphophallus campanulatus (Roxb.) } \\
\text { Blume }\end{array}$ & \\
\hline giant taro & $\begin{array}{l}\text { Cyrtosperma spp. } \\
\text { Alocasia spp. }\end{array}$ & \\
\hline
\end{tabular}

mediate technology' or 'appropriate technology', but most of the conceptual philosophy of such work has been derived primarily from the conventional scientific approaches to the developed world, and has neglected the very considerable corpus of traditional knowledge relating to tropical crops that has been accumulated over centuries or millenia within the societies that grow and use them. Indeed, there has often been a tendency among those who have received a modern scientific education to reject traditional technologies as 'primitive' and fit only to be displaced by sophisticated modern systems, even although the latter may sometimes represent sub-optimal technologies for the situation [Coursey 1978a; IDS 1979]. In the case of the tropical root crops, the neglect of the traditional wisdom is especially unfortunate, as the underlying philosophies of the cultures in which they are grown are extremely alien to those of Europe, within which scientific thinking developed [Coursey 1978a]. The main thesis of this paper is that this store of traditional knowledge, especially of the post-harvest technology of tropical root crops, has remained largely untapped, but possibilities nevertheless exist for the interaction of modern scientific concepts with these traditional systems.
The main features of this rather disparate group of crop products which influence their post-harvest technology, whether in traditional or in sophisticated systems, need to be considered. In any post-harvest situation with perishable materials the first, most fundamental decision to be taken is: should a particular crop product be stored in its natural fresh state, or should it be processed soon after harvest into some more durable form?

Unlike grains and similar crops, root crops are of inherently high moisture content, usually over 50 per cent, often around 60 to 70 per cent and occasionally higher. This governs virtually all further considerations that bear on their post-harvest technology: other differences from durable products are summarised in Table 2. All staple foods are inherently of low-unitvalue, as the carbohydrate element is economically the least valued portion of the diet (although in tropical food habits it is often the conceptual core of the dietary pattern). Although there is a great variation in preference between individual staples, which may be reflected in relative prices-eg in West Africa, yam is so greatly preferred as to command five times or more the price of cassava-in general carbohydrate foods 
tend to be valued largely on the basis of their calorific value. A food material which is more than half water must necessarily have a lower unit-weight-value than those of lower moisture content. Additionally, compared with grains, root crops are bulky and awkward to handle, and losses due to peeling may be as much as 10 to 30 per cent. Root crops, therefore, necessarily tend to be of low-unit-cost even when compared with other staples and this generally precludes the use of sophisticated modern techniques such as refrigeration or controlled atmosphere storage, such as are commonly used for other high-unit-cost horticultural products. These considerations make attention to simple traditional technology especially appropriate with this group of crop products, especially as the costs of sophisticated storage techniques are higher in relation to possible benefits than with higher unit value commodities.

The products of this group of crops are still living after they have been separated from the growing plant at harvest, and the respiratory activity that is needed to supply the energy required by these life processes implies that throughout the post-harvest period, part of their total mass is continually being converted from starch to carbon dioxide and water, implying a steady loss of mass. Appreciable weight loss from this process is thus inherent in storage and adequate supplies of atmospheric oxygen are necessary for the respiratory process, and thus life, to be maintained. Similarly, storage life, even when as with some of the yams this lasts several months, is finally terminated by the organ's natural biological function as part of the plant from which it came, usually the natural breakage of dormancy. Most root crops, other than cassava, have a relatively long inherent storage life of weeks up to several months, in contrast to other perishables such as fruit whose life is normally quite short, being measured in days or at the most a week or two [Coursey and Proctor 1975]. This concept of inherent storage life has been more fully developed elsewhere [Coursey 1982].

The edible portions of the root crops, other than cassava, are organs of dormancy whose natural function is to maintain the plant through adverse (cold or dry) parts of the year. Thus, their storage life is inherently long, but it must eventually end with the breakage of dormancy and consequent sprouting. Even where storage life can be prolonged by the use of sprout inhibitors, deleterious internal changes often commence at about the time when dormancy would naturally break and sprouting occur, while respiratory activity and susceptibility to pathogenic attack increase at

table 2

\section{Comparison of grain and root crop products*}

\begin{tabular}{|c|c|}
\hline grains & root crops \\
\hline $\begin{array}{l}\text { low moisture content, } \\
\text { usually } 10 \% \text { to } 15 \% \text { or less }\end{array}$ & $\begin{array}{l}\text { high moisture content, } \\
\text { typically between } 50 \% \text { to } 70 \%\end{array}$ \\
\hline $\begin{array}{l}\text { small unit size, } \\
\text { typically less than } 1 \text { gram }\end{array}$ & $\begin{array}{l}\text { large unit size, } \\
\text { typically } 5 \mathrm{~g} \text { to } 5 \mathrm{~kg} \text {, sometimes larger }\end{array}$ \\
\hline $\begin{array}{l}\text { very low respiratory rate, } \\
\text { therefore very small generation of heat }\end{array}$ & $\begin{array}{l}\text { high to very high respiratory rate, } \\
\text { and heat production therefore high }\end{array}$ \\
\hline $\begin{array}{l}\text { hard texture, } \\
\text { therefore not easily damaged }\end{array}$ & $\begin{array}{l}\text { soft texture, } \\
\text { therefore easily damaged }\end{array}$ \\
\hline $\begin{array}{l}\text { stable, } \\
\text { natural shelf life potentially several years }\end{array}$ & $\begin{array}{l}\text { perishable, } \\
\text { natural shelf life of from a few days to at best several } \\
\text { months, according to crop and storage system }\end{array}$ \\
\hline $\begin{array}{l}\text { losses, } \\
\text { mainly caused by external agents, eg moulds, } \\
\text { insects and rodents }\end{array}$ & $\begin{array}{l}\text { losses, } \\
\text { caused partly by external agents, eg bacteria and fungi } \\
\text { and partly by endogenous factors, eg respiration and } \\
\text { sprouting }\end{array}$ \\
\hline
\end{tabular}

"based on FAO/UNEP 1981 
about the same time. Because of the high water content of root crop products, their mechanical strength is relatively low; although this factor is fairly widely appreciated with high-unit-cost horticultural produce, such as soft fruit, which are conspicuously susceptible to mechanical damage and appropriate precautions taken, it is realised much less often that even such apparently solid items as potatoes and yams are also extremely liable to mechanical injury [Coursey and Booth 1977]. Much attention needs to be paid to the preservation of the physical integrity of the crop products: this is a field where the respect that the subsistence agriculturalist traditionally pays to his basic subsistence crop has a great part to play. As has been indicated by Coursey and Booth [1977], the root crops are all susceptible in various circumstances to pathogenic damage, which may be caused either by infection which takes place in the field before harvest, or after harvest, when the attack is often associated with wounding or more especially bruising, which further emphasizes the need to avoid mechanical damage: a factor of which most subsistence farmers are well aware with their traditional crops, but often neglect with recently-introduced cash crops.

The use of modern chemical fungicides, insecticides, etc doubtless has a part to play in enhancing the storage life of some root crop products, but many of the most effective of these compounds involve toxicological hazards to man or present other environmental hazards, and their use must therefore always be carefully controlled and conducted only in accordance with appropriate legislation, which can sometimes limit their usefulness. Traditional technology has in some cases, as will be discussed later, developed the use of simple, locally available compounds to limit the invasion of wound pathogens into damaged tissues.

\section{Considerations Specific to the Different Crops}

Within the broad principles indicated above, emphasis must vary greatly from crop to crop as to which is the most effective system of post-harvest technology to apply, especially with regard to the fundamental decision: whether to store fresh or to process. The botanical, and therefore the physiological and biochemical characteristics of the different crop products vary greatly: although generally loosely referred to by agronomists as 'roots', some are true roots, some root tubers, some stem tubers and some cormous organs. The following sections of this article review some of the available information on the traditional post-harvest technologies of tropical societies, and indicate where interaction with modern scientific thinking has occurred or could be potentially useful. Nevertheless, it must be emphasized that this article can do little more than indicate that there are enormous fields of ignorance in the overall subject area, where further research could be beneficial.

\section{Cassava}

Cassava, yuca, tapioca or manioc, Manihot esculenta Crantz, in terms of total tonnage of production in the developing world, is more important than all the other root crops together. It is also unique among the major root crops, in that edible roots are not organs of dormancy, and have no natural function in the preservation of the plant through an adverse season. They are thus not inherently adapted to survival in the isolated state. Most wild Manihot spp. do not undergo dormancy and in many cases do not produce thickened roots: it may be that the edible cassava roots, which are formed by a process of secondary thickening of a proportion of the normal fibrous roots, represent simply an abnormal anatomical condition which, after appearing adventitiously, has been selected for cultivation because it makes the plant a better food source. The swollen roots appear to have little biological function, although they can contribute to the support of the plant when cassava is grown under conditions of periodic drought. It is well known that cassava roots, once detached from the growing plant will not normally keep for more than a few days [Ingram and Humphries 1972; Rickard and Coursey 1981]. which may be related to this lack of biological function, although there is considerable variation between cultivars in endogenous storage life. The traditional way of overcoming this difficulty is to leave the plants in the ground until needed, and once harvested, either to utilise the roots immediately or to process them into some form of dried product: however, this practice unnecessarily occupies large areas of land, estimated [Ingram and Humphries 1972] as three quarters of a million hectares across the tropical world. This was acceptable at one time when human populations were much less dense than today, but is less so under present-day conditions.

A traditional storage technique developed by the Amerindians of Amazonia, probably related to the practice of leaving the standing crop in the ground, is burying the roots in pits or trenches: in areas subject to flooding, the pits could be sealed with a layer of clay and under favourable conditions the roots were said tokeep for several months. This practice was mentioned by early explorers in the Amazon in the $1600 \mathrm{~s}$ and not dissimilar techniques have been reported in other parts of the world to which cassava has been taken in recent centuries [Rickard and Coursey 1981|. It is only recently that research has established [Booth 1974; Booth and Coursey 1974| that the environmental conditions established in such underground storage systems are such as to favour 'curing' or wound healing, 
a process involving suberisation and the formation of wound periderm, which to a large degree inhibits both the endogenous physiological breakdown ('vascular discolouration') that is normally the first phase of the deterioration of cassava roots, and also secondary pathogenic invasion. This interaction of modern scientific/technological investigations with studies of ancient traditional storage practices is now leading to the development of improved storage and transportation systems, as it is now understood that the avoidance of water stress is essential to the long-term preservation of cassava roots.

Similarly, it has long been known by cassava farmers in many parts of the world that if cassava roots are harvested with a short length of stem attached, the storage life of the roots will be enhanced. This has recently attracted the attention of research workers |Lozano et al 1978 and the physiological factors involved are currently being elucidated: already, a technique of pruning the crop almost to ground level a few weeks before harvest has been developed, which has been found to enhance root storage life.

Whatever improvements are being made in fresh cassava storage, most cassava is processed into some form of dried, durable food product soon after harvest, and this practice is likely to continue in many parts of the world. The toxicity of the roots, due to the presence of the cyanogenic glucosides, linamarin and lotaustralin, which on hydrolysis yield the intensely poisonous hydrocyanic (prussic) acid, has provided a stimulus to the development of processing techniques as has their highly perishable nature for / Coursey 1973; Cooke and Coursey 1981 ।. A wide variety of traditional food preparation techniques are used for processing cassava in different parts of the world, many of which simultaneously remove a substantial proportion of the toxin and produce a dry, stable food product. These processes involve maceration, soaking, squeezing, fermentation, boiling or roasting, or a combination of these, and result in the elimination of at least part of the hydrocyanic acid by solution or volatilisation. The essential principles of many of these techniques were developed by the Amerindians of tropical America, probably as long as 4,000 years ago, and are still extensively used there. Some of these techniques have been transferred to other parts of the tropics with the introduction of the cassava plant, while other methods were invented independently when the cassava plant spread to the Old World in post-Colombian times |Lathrap 1973; Montaldo 1979; Lancaster et al 1982). An especially brilliant Amerindian invention is the tipiti. a woven wicker press used for squeezing the cyanide-containing water from the mashed cassava, after which the partially de-watered mash is heated in metal or ceramic pans, until a dry, stable granular flour is produced.
Other simple techniques have been developed in Africa and South Eastern Asia to produce stable, nontoxic products from cassava, many of which involve soaking in running water, or a combination of this with other retting techniques, which result in the production of a relatively pure starch. Sun-drying (or occasionally fire- or smoke-drying) of cassava root slices and subsequent pounding into coarse flour is also widely practised in the Old World.

The impact of modern technology on cassava processing has been most noticeable in Brazil, where the production of the traditional farinha de mandioca is now conducted to a very considerable degree on the industrial scale, using hydraulic presses instead of the traditional tipiti, but otherwise involving essentially a scaling-up and rationalisation of the traditional process, and its adaptation to the small-factory level. Although much effort has been devoted in West Africa to a comparable conversion from traditional to industrial manufacture of the very similar product gari (the basic technology for the manufacture of which was introduced from Brazil in the 19th century), so far only a very small number of industrial scale plants are in operation. The main constraint appears to be economic, rather than technological, in that any gari factory has to compete with the traditional product, in the manufacture of which much uncosted labour is used. It has been shown by Ngoddy [1976] that relatively simple, partially mechanised systems based on traditional technology may well be more successful than sophisticated, high-technology systems.

\section{Yams}

Yams are probably the most important of the traditional root crops in which the edible product is an organ of dormancy. The Guinea yams, Dioscorea rotundata Poir. and $D$. cayenensis Lam. are in general the most highly preferred carbohydrate staple in Africa, while $D$. alata $\mathrm{L}$. and $D$. esculenta (Lour.) Burk are more widely used in other areas, the Caribbean and Pacific. Many other species are of local importance.

The tubers of the major edible yam species are an evolutionary adaptation which enable the plant to survive the hot dry season of savanna areas in a dormant state, and so are inherently well suited to storage in their natural state when being utilised as food: in fact, unlike cassava, yams are generally kept as fresh, rather than as processed food. The endogenous storage life varies greatly between species and even between cultivars, but the best-keeping cultivars may easily be stored for three to four months, or exceptionally, even longer [Coursey 1967]. All yamgrowing cultures have developed traditional storage systems and structures for yam tubers, the basic principles of which are always the provision of adequate 
ventilation, access for regular inspection and protection from direct sunlight [Wilson nd]. Exposure to sun in the field for a few days immediately after harvest may assist in the development of the beneficial 'curing' or wound healing effect, as indeed it does for most tropical root crops [Booth 1964], but for long-term storage, a cool, moist, well shaded location is optimal. Prolonged exposure to the sun should be avoided, as damagingly high internal temperatures of $40^{\circ} \mathrm{C}$ can easily be achieved |Rickard and Coursey 1979|: this is well understood in most subsistence agricultural economies, and is related to the traditional high regard in which this crop is held in most societies in which it is grown.

The storage life of yam tubers is finally terminated by the endogenous breakage of dormancy, followed by sprouting. Traditional practice is normally to break off the emergent sprouts when they are $20-30 \mathrm{~mm}$ long, unless the tubers are required for planting. This has been shown to delay further sprout development [Martin 1977], extending storage life perhaps by as much as a month, and reduces respiratory weight loss. The chemical sprout suppressants that are so successfully used with potatoes are mainly ineffective when applied to yams, as the bud primordia on which they act are not formed in the yam until near the end of dormancy, whereas in potato and sweet potato they are formed before harvest [Passam 1978]. Pathogenic factors are also of the greatest importance in the storage of yam tubers [Noon 1978], and although the matter has only recently received scientific study [Passam et al 1976], most yam-growing societies are aware that while abrasions or bruises on yams can rapidly lead to extensive decay, clean cuts can usually heal. Traditionally, therefore, damaged portions are cleanly cut out before storage, and the cut surface often covered with an alkaline material such as wood ashes, ground chalk or lime to inhibit microbiological infection. Modern systemic fungicides such as thiabendazole and benlate have been shown to be useful in controlling decay in yams in certain situations, but are not very widely used. The concept of using sophisticated refrigerated storage systems for yams has been extensively promulgated in recent years, but its practicability is highly questionable as the major edible yams are subject to chilling damage at relatively high temperatures (around $10^{\circ} \mathrm{C}$ or even higher: [Coursey 1968b]), while further, the need for extension of storage life that refrigerated storage could possibly achieve would be required for only two or three months of the year, and so is unlikely to be economic unless other uses could be found for the installations for the rest of the year. A more favourable possibility exists for the use of gamma irradiation, which has been shown to inhibit sprouting substantially $\mid$ Adesuyi and Mackenzie 1973] and could without great difficulty be applied before the yams are stored in traditional barns. Such treatment could thus be applied without major disruption to traditional storage and marketing practice.

Long-distance trade of up to several hundred kilometres in fresh yam is known to have existed in West Africa for hundreds of years whereas the comparatively recent trade in cassava is largely confined to the processed product [Coursey 1978b]. A proportion of the yam crop is nevertheless traditionally processed by slicing, parboiling, sun-drying and pounding or grinding into flour. The processed product is popular in the Yoruba-speaking districts of Nigeria [Adenuga 1979], but in most other yam-growing areas of the world it is largely only misshapen, damaged or partially decayed yams, unsuitable for storage, that are used for processing. A number of technological inputs are being introduced to the traditional process, such as the use of small power-operated mills for grinding the dry slices into flour, rather than the laborious traditional pestle and mortar method. Several small factory-scale at tempts to manufacture more sophisticated products in West Africa and the Carribbean have been commercially unsuccessful however [Coursey and Ferber 1979], partly because insufficient attention was paid to the simulation of the traditional food product.

Some yams, notably the African $D$. dumetorum (Knuth) Pax and the Asiatic D. hispida Dennst., are highly toxic on account of the presence of water-soluble alkaloids of the dioscorine group. Many traditional technologies exist for detoxifying these yams, all based on slicing or grating the tubers and leaching out the alkaloid with fresh or salt water: test methods to determine whether the detoxification has been adequately carried out, by testing the acridity of the leach water, have also been developed in subsistence societies [Coursey 1967]. More recently [Sulit 1967] the traditional soaking/leaching methods have been adapted to small-scale factory use, for edible starch manufacture, in South East Asia.

\section{Taro and other aroids}

Taro or 'old' cocoyam (Colocasia esulenta (L) Schott) and tannia, ocumo or 'new' cocoyam (Xanthosoma sagittifolium (L) Schott) are important food crops in many tropical countries, especially in West Africa, the Caribbean and the Pacific [Coursey 1968a]. They are frequently consumed shortly after harvest, and storage is therefore largely avoided as they are usually available throughout a large part of the year. Except in the Pacific area, they are frequently regarded as inferior to yams and very little is known about the post-harvest behaviour of the corms, which constitute the main edible portion. Although there are reports of storage with losses of only $12-15$ per cent after four to six months in West Africa, other studies report much 
more rapid deterioration. The corms can exhibit true dormancy, but in normal practice are often harvested when the plant is still actively growing: this may well be responsible for the great variation in storage behaviour found, and should repay further investigation. Such traditional storage systems as have been described in West Africa [ Nwana and Onochie 1979] and southern China [Plucknett and White 1979] involve piling the corms into heaps covered with leaves and then with soil, or sealing them in leaf-lined pits in the ground, the essential feature of these storage systems being the maintenance of 'curing' conditions, to stimulate wound healing and discourage the spread of decay.

Traditional processing into chips or flour is carried out in much the same way as with yams, with the difference that a prolonged boiling of the slices, rather than a simple parboiling, is needed to remove the acrid flavour. Throughout much of the Polynesian areas of the Pacific, taro is commonly pounded or ground with water into a paste known as poi, the consistency of which depends on the water content..In Hawaii, where some aspects of traditional Polynesian culture survive within the high-cost, market-oriented American economy, the production of poi has been partially mechanised, using mechanical grinders for the preparation of the poi and polythene sachets for its marketing |Begley 1979|.

The other edible aroids of the genera Cyrtosperma. Amorphophallus and Alocasia are only of local utilisation, and little is known of their post-harvest technology: in general, they are used within a few days of harvest, and storage is thus avoided, although the stems of Alocasia can be kept under favourable conditions for several weeks.

\section{Potatoes}

The potato (Solanum tuberosum L.), although originally of tropical montane origin, has been developed as an economic crop mainly in temperate countries. As a food associated mainly with expatriates (vide, the Ibo name $j i$-beke $=$ white man's yam), potatoes are now regarded in many tropical countries as a luxury vegetable commanding a sufficiently high price for cold storage to be an economic proposition. The crop has, however, a much greater potential, not only for the high-altitude tropics, but at medium and possibly even low altitudes [French 1972]. Although cold storage will doubtless remain important, especially for seed potatoes, the development of the potato as a major staple food will depend largely upon the development of cheaper storage systems [Booth and Proctor 1972], such as night ventilation.

In the altiplanos of the Andes, where the potato was first domesticated in early pre-Colombian times, various traditional systems were developed to store potatoes fresh, or to process them into more durable form. Potatoes, like yams, have an inherently long storage life during their pericd of dormancy, and at the relatively low temperatures of the altiplanos, respiratory loss is slight. However, infestation by the potato tuber moth is a major post-harvest problem and traditionally, infestation is minimised by inter-layering the stored tubers with leaves of the herb muna, the volatile essential oils of which appear to have insect repellant properties.

The freeze-drying process used on the altiplanos for the manufacture of processed potato products, notably chuna, is especially interesting as an example of a simple, but highly effective traditional technology. This technique involves exposing whole or sliced potatoes to sub-zero night temperatures, when freezing destroys their cellular integrity, and squeezing or trampling out the juice during the daytime when, although the ambient temperatures remain relatively low, intense insolation occurs at the high altitude, while the low atmospheric pressure facilitates evaporation of water: the process is repeated for several nocturnal diurnal cycles, until a dry product suitable for storage is obtained [Salaman 1949; Werge 1979]. This technique is, of course, only applicable in the high-altitude tropics, where sub-zero night temperatures occur, but it serves to demonstrate the advanced level of thinking that was often applied in very ancient times to technological developments in pre-literate societies possessed of relatively limited material resources.

\section{Sweet potatoes}

The sweet potato (Ipomoea batatas (L.) Lam.) is extensively grown in the tropics, although it is much better known as a summer crop in warm temperate countries such as southern USA, Japan and New Zealand. It is largely in these developed countries that sophisticated storage technologies have emerged [Edmond 1971]. These have largely concentrated on the protection of the roots from cold during winter, as the sweet potato is highly subject to chilling injury, commencing at temperatures around $12^{\circ} \mathrm{C}$. It has been primarily against this background that curing treatments have been developed, involving exposure to relatively high temperatures and humidities [Booth 1974] for a few days before the tubers are placed in storage. This curing process results in the development of a suberised layer in any wounds present, which inhibits invasion by pathogens: after 'curing', the roots may safely be stored at lower temperatures, around $14^{\circ} \mathrm{C}$ being optimum. The importance of protection from cold was known to the early Maori, who used underground pits, kept warm by the respiratory heat of the produce, to store sweet potatoes through the winter. Under tropical conditions, the crop is well known as being extremely 'wasty', and, for this reason 
storage avoidance, ie harvesting only as required, is generally practised. Short term storage of sweet potatoes in small quantities in the home can be extended by exposure to warmth or smoke from fires, which presumably has some "curing' effect, and to a limited extent storage in grass or leaf-lined pits similar to those used for taro is also practised [Siki 1979]. Pathogenic invasion appears to be one of the main problems, while unlike most root crops infestation by weevils (Cylas spp.), initially pre-harvest, can have major post-harvest effects in promoting deterioration.

\section{Conclusions}

The traditional storage and processing techniques for root crops, described here, are not always ideal; some better, more sophisticated alternatives exist, but in particular the traditional systems are often capable of substantial improvement. The concepts around which many of them were originally conceived were severely limited by the resources available, and the cultures within which they evolved were essentially ecocentric rather than technocentric in their philosophies. The technologies were developed for, and are mostly best adapted to, the small or medium scale systems of the subsistence sector. It may be that more sophisticated systems using modern techniques such as refrigerated, controlled atmosphere or hypobaric storage may become optimal in relation to international trade and to the expanding local market economies that are being generated by the rapidly increasing urbanisation of the tropical world. Nevertheless, it is suggested very positively that these traditional techniques, which have been refined in some cases over thousands of years, are generally well worth scientific study with a view to their possible improvement; their better adaptation to modern conditions; or to the injection of concepts derived from the more technocentric nontropical cultures. One need only cite two of the examples given above, the controlled pre-harvest pruning of cassava to extend post-harvest life of the roots, or the use of gamma irradiation to delay breakage of dormancy in yams, to see how a blending of traditional and modern technology can be possible.

Many of the techniques traditionally adopted for the preservation of tropical root crops result from very considerable ingenuity in optimising storage or processing technologies in low-resource environments, even though a formal knowledge of scientific principles was absent. Simultaneously, the adverse environmental impact of traditional technology is usually minimal, compared with the solutions offered by modern technology. It is therefore suggested that the entire field of traditional technology in the post-harvest sector-and indeed in other areas-is worth closer scientific study than it has hitherto received, especially with regard to tropical root crops and other non-grain staple foods.

\section{References}

Adenuga, A. O., 1979, 'Processing and storage of yam in Nigeria', in D. L. Plucknett (ed), Small Scale Processing and Storage of Tropical Root Crops, Westview Press, Boulder, Colorado

Adesuyi, S. A. and J. A. MacKenzie, 1973, The inhibition of sprounting in stored yams, Dioscrorea rotundata Poir., by gamma radiation and chemicals', Radiation Preservation of Foods, International Atomic Energy Authority, Vienna

Begley, B. W., 1979, 'Taro processing in Hawaii: an economic and historical perspective', in D. L. Plucknett (ed), op cit

Booth, R. H., 1974, 'Post-harvest deterioration of tropical root crops', Tropical Science, vol 16 no 1, pp 49-63

- and D. G. Coursey, 1974, 'Storage of cassava roots and related post-harvest problems', in Cassava Processing and Storage, IDRC Monograph, IDRC-031e, International Development Research Centre, Ottawa

- and F. J. Proctor, 1972, 'Considerations relevant to the storage of ware potatoes in the tropics', PANS, vol 18 no 4 , pp 408-32

Cooke, R. D. and D. G. Coursey, 1981, 'Cassava: a major cyanide-containing food crop', in B. Vennesland et al (eds) Cyanide in Biology, Academic Press, New York and London

Coursey, D. G., 1967, Yams, Longmans Green, London

-1968a, 'The edible aroids', World Crops, vol 20 no 3, pp 2530

$-1968 \mathrm{~b}$, 'Low temperature injury in yams', Journal of Food Technology, vol 3 no 2, pp 143-50

-1972 , 'Biodeteriorative losses in tropical horticultural produce', in A. H. Walters and E. H. Huek-van der Plas (eds), Biodeterioration of Materials, Applied Science Publishers, London

-1973 , 'Cassava as food: toxicity and technology', in Chronic Cassava Toxicity, IDRC Monograph, IDRC-010e, International Development Research Centre, Ottawa

$-1978 \mathrm{a}$, 'Some ideological considerations relating to tropical root crop production', in E. H. Fisk (ed) The Adaptation of Traditional Agriculture, Australian National University, Canberra

$\mathbf{- 1 9 7 8 b}$ 'Root crops and their utilisation in West Africa', in E. H. Fisk (ed), op cit

-1981, 'Traditional post-harvest technology of tropical perishable staples', Industry and Environment, UNEP News letter, vol 4 no 1 , pp 10-14

-1982, 'Post-harvest losses in perishable foods of the developing world', Proceedings of NATO Advanced Study Institute on Post-harvest Physiology and Crop Protection, Sounion, Greece, Plenum Press, New York

- and R. H. Booth, 1977, 'Post-harvest problems of non-grain staples', Acta Horticulturae, vol 53, pp 23-33

-and C. E. M. Ferber, 1979, 'The processing of yams', in D. L. Plucknett (ed), op cit

- and P. H. Haynes, 1970, 'Root crops and their potential as food in the tropics', World Crops, vol 22 no 4, pp 261-5

- and F. J. Proctor, 1975, 'Towards the quantification of post-harvest loss in tropical horticultural produce', Acta Horticulturae, vol 49, pp 55-66

de Vries, C. A., J. D. Ferweda and M. Flach, 1967, 'Choice of food crops in relation to actual and potential yields in the tropics', Netherlands Journal of Agricultural Science, vol 15 no 4 , pp $241-8$ 
Edmond, J. B. 1971, Sweet Potatoes: Production, Processing, Marketing, Avi Publishing Corporation, Westport, Connecticut

FAO/UNEP, 1981, Food Loss Prevention in Perishable Crops, report of $\mathrm{FAO} / \mathrm{UNEP}$, expert consultation on the reduction of food losses in perishables of plant origin, FAO, Rome

French, E. R., 1972, Prospects for the Potato in the Developing World, Centro Internacional de le Papa, Lima, Peru

Ingram, J. S. and J. R. O. Humphries, 1972, 'Cassava storagea review', Tropical Science, vol 14 no 2, pp 131-48

Institute of Development Studies, 1979, 'Rural development: whose knowledge counts?', Robert Chambers (ed), Bulletin vol 10 no 2

Lancaster, P. A., J. S. Ingram, M. Y. Lim and D. G. Coursey, 1982, 'Traditional cassava-based foods: a survey of processing techniques', Economic Botany, vol 36 no 1, pp 12-45

Lathrap, D. W., 1973, 'The antiquity and importance of long long distance trade relationships in the moist tropics of preColombian South America', World Archaeology, vol 5 no 2, pp $170-86$

Lozano, J. C., J. H. Cock, and J. Castaño, 1978, 'New developments in cassava storage', in Proceedings of the Cassava Protection Workshop, Centro Internacional de Agricultura, Cali, Colombia

Martin, F. W., 1977, 'Prolonging the storage life of yams by removal of shoots and by treatment with gibberelic acid and waxes', Tropical Root Tuber Crop Newsletter, vol 10, pp 39-44

Montaldo, A., 1979, La Yuca o Mandioca, Instituto Interamericano de Ciencias Agricolas, San Jose, Costa Rica

Ngoddy, P. O., 1976, 'Gari mechanisation in Nigeria: the competition between intermediate and modern technology', in N. Jequier (ed), Appropriate Technology: Problems and Promises, OECD Development Centre, Paris

Noon, R. A., 1978, 'Storage and market diseases of yams', Tropical Science, vol 20 no 3, pp 177-88
Nwana, I. E. and B. E. Onochie, 1979, 'The technical and social problems of taro processing and storage in Nigeria', in D. L. Plucknett (ed), op cit

Passam, H. C., 1978, Dormancy of yams in relation to storage', in Yams-Ignames, Proceedings of an international seminar on yams, Buea, Cameroun, International Foundation for Science, Stockholm

-S. J. Read and J. E. Rickard, 1976, 'Wound repair in yam tubers; the dependence of storage procedures on the nature of the wound and its repair', Tropical Science, vol 18 no 1 , pp 1-11

Plucknett, D. L. and M.S. White, 1979, 'Storage and processing of taro in the People's Republic of China', in D. L. Plucknett (ed) op cit

Rickard, J. E. and D. G. Coursey, 1979, 'The value of shading perishable produce after harvest', Appropriate Technology, vol 6 no 2 , pp 18-19

- and D. G. Coursey, 1981, 'Cassava storage: part 1: storage of fresh cassava', Tropical Science, vol 23 no 1, pp 1-32

Salaman, R. N., 1949, The Historical and Social Influences of the Potato, Cambridge University Press

Siki, B. F., 1979, 'Processing and storage of root crops in Papua New Guinea' in D. L. Plucknett (ed), op cit

Sulit, J. I., 1967, 'Method of processing and utilisation of nami (Dioscorea hispida) tubers', Araneta Journal of Agriculture, vol 14 no 4, pp 203-21

Tindall, H. D. and F. J. Proctor, 1980, 'Loss prevention in horticultural crops in the tropics', Progress in Food and Nutrition Science, vol 4 nos 3-4, pp 25-39

Werge, R. W., 1979, 'Potato processing in the central highlands of Peru', Ecology of Food and Nutrition, vol 7 no 4, pp 229-34

Wilson, J. E. (nd), Careful Storage of Yams, Commonwealth Secretariat, London 